\title{
Piecing together the biogeographic history of Chenopodium vulvaria L. using botanical literature and collections
}

Quentin J Groom

This study demonstrates the value of legacy literature and historic collections as a source of data on environmental history. Chenopodium vulvaria L. has declined in northern Europe and is of conservation concern in several countries, whereas in other countries outside Europe it has naturalised and is considered an alien weed. In its European range it is considered native in the south, but the northern boundary of its native range is unknown. It is hypothesised that much of its former distribution in northern Europe was the result of repeated introductions from southern Europe and that its decline in northern Europe is the result of habitat change and a reduction in the number of propagules imported to the north. An historical analysis of its ecology and distribution was conducted by mining legacy literature and historical botanical collections. Text analysis of habitat descriptions written on specimens and published in botanical literature covering a period of more than 200 years indicate that the habitat and introduction pathways of $C$. vulvaria have changed with time. Using the non-European naturalised range in a climate niche model it is possible to project the range in Europe. By comparing this predicted model with a similar model created from all observations it is clear that there is a large discrepancy between the realized and predicted distributions. This is discussed together with the social, technological and economic changes that have occurred in northern Europe, with respect to their influence on C. vulvaria. 
1 Author: Quentin J. Groom

2 Affiliation: Botanic Garden Meise, Bouchout Domain, Nieuwelaan 38, 1860 Meise, Belgium

3 Email: quentin.groom@br.fgov.be 


\section{Introduction}

5 Legacy biodiversity literature is a potential source of useful information on the past distributions

6 of organisms. While these texts have always been available in academic libraries, their

7 accessibility and discoverability has been significantly enhanced by projects such as the

8 Biodiversity Heritage Library (www.biodiversitylibrary.org) and other online digital sources. The

9 ability to search a whole corpus of historical literature for a Latin name of an organism dramatically increases the accessibility of this information and makes literature searches possible that once would have been unfeasible. In parallel, the widespread digital imaging of herbarium specimens and transcription of their labels has also made these data considerably more accessible, which, combined with historic literature, has created a large pool of information from which the phytogeographic historian can draw evidence (Vellend et al., 2013).

Chenopodium vulvaria L., is a small, inconspicuous species that grows largely in places disturbed by humankind. It is not remarkable morphologically, but it is nonetheless distinctive due to its foul smell, which is described as similar to that of rotten fish. Its distinctiveness makes it particularly suited to a study using historic literature, because there is less concern that published accounts refer to other species as a result of misidentification.

C. vulvaria is currently a red-listed species in several countries including Sweden (Ferrez, 2005). In Great Britain, Ireland and Flanders, comparisons of atlas data show that $C$. vulvaria is in severe decline (Preston et al., 2002; Van Landuyt et al., 2006). In contrast, it has naturalised in California (Calflora, 2014), Argentina (Planchuelo, 1975; Giusti, 1997), Chile (Boelcke et al., 1985) and Australia (Atlas of Living Australia, 2014).

C. vulvaria is widespread in countries bordering the Mediterranean and eastward to Afghanistan and Mongolia (Jalas \& Suominen 1980; Meusel, Jäger \& Weinert, 1992). Yet it is clear from historical literature and specimens that it was common in parts of northern Europe during the $18^{\text {th }}$ and $19^{\text {th }}$ centuries. Turner (1548) wrote "It groweth muche aboute the walles in Bon in Germany"; Bucher (1806) wrote in the Flora of Dresden "An den strassen der vorstadt und sonst gemein" translated as "By the streets of suburbs and usually common"; Curtis (1777) stated "This species is very common in the neighbourhood of London..." and Hooker (1821), in his flora of Scotland, 
"...per totum Belgium passim", which can be translated as "everywhere throughout Belgium" and in France it was described as "commun" and "trés commune" (i.e. "common" and "very common") on specimens from Narbonne (1846, P04922786) and Paris (1819, P05292341) in the Museum National d'Histoire Naturelle.

The native distribution of C. vulvaria is unknown and its long association with anthropogenic disturbance makes this impossible to determine. Floras in Northern and Central Europe variously describe it either as a native or an archaeophyte, though the evidence for categorizing it in either category is slim and is probably based on the anthropogenic habitats that $C$. vulvaria often inhabits.

Many other members of the Amaranthaceae live in disturbed, nutrient rich habitats and may be halophytic. C. vulvaria itself is often found in disturbed, eutrophic and coastal habitats. In general, species of such habitats are increasing and spreading in northern Europe (Wróbel, Tomaszewicz \& Chudecka, 2006; Van Landuyt et al., 2008; Smart et al., 2003; Šerá, 2011; Groom, 2013). So at face value, C. vulvaria appears well adapted to modern habitats in Europe and yet it has declined.

One possible explanation for its apparent decline in northern and central Europe may be a misunderstanding of its former occurrence, its presence in the north being the result of propagule pressure from its heartland in southern Europe, constantly reinforcing the introduced populations in the north. One or many introduction pathways may have existed that delivered C. vulvaria seed outside of its normal range and these pathways have since reduced in importance, causing a collapse in the population. Another possible explanation is change to its former habitat, though the details of its ecology are too poorly known to understand what these changes may have been.

For non-woody plants there are few sources of data to examine recent biogeographic change. Palynology and the study of archaeological remains can be useful, but many species do not have sufficiently distinctive characters to identify them from their remains. In these cases, historical literature and collections may be the only sources of data on their former habitats and locations. Given the shortage of data, an alternative approach, widely used to model the potential distribution of organisms, is bioclimatic modelling. Many studies have used observations from the known native range of a species to extrapolate its potential invasive range (e.g. Macfadyen $\&$ Kriticos, 2012). In ecological theory the potential bioclimatic range is generally considered to be larger than the realized distribution as a consequence of additional non-climatic limitations to 
distribution, such as edaphic factors (Araujo \& Peterson, 2012). However, in the case of $C$. vulvaria the native range is not known and frequent non-persistent introductions mean that the realized distribution predicted from observations may be larger than its true bioclimatic range. For C. vulvaria the location of naturalisation in Australia, North America and South America might be a clearer indication of its bioclimatic range than within Europe, where it is hard to distinguish established from casual occurrences. Assuming that this species is well established and stable in its alien range, we can use the known naturalised range to model the climate envelope and extrapolate this to Europe to identify the areas where the climate is suitable for $C$. vulvaria. In this manner we can indicate those places where this species has been observed but is unlikely to be persistent. A similar approach has been used by Zhu et al. (2012) to predict the source of the invasive insect Halyomorpha halys (Stål, 1855) and has been used by others to model the historical distributions of trees (Benito-Garzón et al., 2008). This approach assumes niche conservatism, but such conservatism is apparently common place and perhaps typical of invasive terrestrial plant species (Townsend Peterson, 2011; Petitpierre et al., 2012)

My hypothesis is that $C$. vulvaria was formally more abundant in northern Europe and its current decline is the result of changes in the introduction pathways and loss of habitat. In this study I draw on botanical literature and specimens to identify habitat change and historic introduction pathways. I use text analysis of habitat descriptions to demonstrate how its habitat has changed over the past 200 years and I use bioclimatic niche modelling to contrast the realized range within Europe with the projected range based upon naturalised occurrences outside Europe.

\section{Methods}

Observation and specimen details were collected in a Common Data Model (CDM) database which is the central component of the EDIT Platform for Cybertaxonomy (Ciardelli et al., 2009; Berendsohn et al., 2011). Two methods were used to extract observations from literature, either XML markup or direct data entry. Digitised treatments were marked up with XML using the GoldenGate editor (http://plazi.org/?q=GoldenGATE, Sautter, Böhm \& Agosti, 2007); uploaded to the PLAZI taxonomic treatment repository (plazi.org) and imported to the CDM database. Alternatively the observation details were copied from the treatment and entered manually into the CDM database using the EDIT Taxonomic Editor (Ciardelli et al., 2009). Observations were collected from the biodiversity literature by reading the Biodiversity Heritage Library corpus systematically after searching for $C$. vulvaria L. and its synonyms C. foetidum Lam., C. olidum 
Curt., Atriplex vulvaria Crantz and Vulvaria vulgaris Bubani. Other published observations were gathered from publications in the Library of the Botanic Garden, Meise. A list of the sources of observations of $C$. vulvaria is available in supplementary file S1. A complete survey of nondigitised literature is unfeasible, but there was an effort to check multiple floras of every European country and any other country with a temperate climate suitable for C. vulvaria.

Digitised observation data were also gathered from databases, primarily from the Global Biodiversity Information Facility (GBIF) (data.gbif.org, accessed 08 Nov 2013; see supplementary file S2), but also from the Atlas of Living Australia (2014); the Botanical Society of Britain and Ireland (2013) and Herbaria@home (2013). Scientific articles and websites containing observations were also discovered using search engines (scholar.google.be; google.be). Data were standardised and imported directly into the CDM database.

Specimen data were gathered from herbaria by transcription of label information. Specimens from 31 herbaria are included in the study; their abbreviations follow the Index Herbariorum (http://sciweb.nybg.org/science2/IndexHerbariorum.asp): ABS, ALA, B, BBB, BC, BIRM, BM, BR, C, CONC, FABR, FRU, HFLA, K, L, LISU, M, MANCH, MW, NYS, P, PRC, RNG, SO, SLBI, SOM, SOMF, UBC, UC, WAG, WU and others contributing data to GBIF (Herbaria names in supplementary file S2). Many other herbaria and herbarium catalogues were searched without finding specimens and several herbaria were contacted and either contained no specimens or did not respond. Undoubtedly there are more specimens and observations of $C$. vulvaria to be discovered, but I believe these to be a representative sample and a large proportion of those that exist. Undated specimens were not used in the study; however, it is usual for published observations to be undated and therefore the publication date was used instead. In studying biographical information of collectors it is clear that most undated observations in old floras are within 35 years of the publication date and authors tend to provide dates when those dates are a long time before the publication date. In total 2456 observations were collected from specimens and literature. These data span 465 years from 1548 to 2013, though there are only two observations from the $16^{\text {th }}$ century, two from the $17^{\text {th }}$ century and nineteen from the $18^{\text {th }}$ century.

\section{Text analysis of habitats}

The text describing the habitat of $C$. vulvaria was collected from 104 floras, 33 scientific articles, 
119 specimens and 5 websites, covering the years 1787 to 2014 . The texts were written in 12 languages, English (35\%) German (20\%), French (17\%), Latin (12\%), Dutch (4\%), Italian (3\%), Portuguese (3\%), Spanish (3\%), Hungarian (1\%), Danish (1\%), Catalan (1\%) and Czech (<1\%). Each description was broken down into tokens consisting of either single words or short phrases describing a single aspect of the habitat. Thus the description "In Straßen, an Häusern, Stallungen, Düngerstätten" was broken down into the tokens "Straßen" (roads), "an Häusern" (near houses), "Stallungen" (stables) and "Düngerstätten" (manure heaps). This process created 475 habitat tokens. These tokens were then translated to English using native speakers of English, German, French and Dutch and for other languages a combination of Google Translate (translate.google.be) and the multilingual collaborative dictionary Wiktionary (wiktionary.org). To conduct the analysis it was necessary to reduce the number of habitat terms, which was done in two stages. The anglicized tokens were first simplified to closely related terms. Thus the terms "by foot of the city walls", "along walls", "under walls", "mud walls", "foot of walls", "under walls", "under a wall" and "foot of the church yard wall" were all replaced by "by walls". This process reduced the number of habitat words to fifty. These fifty words were then arranged into logically related categories. Thus "by walls", "by fences" and "by hedges" were grouped together under the term "boundaries". This reduced the number of habitat categories to fifteen: animal waste, boundaries (including walls), coastal, disturbed and grazed land, dry \& bare soil, habitation, hills, horticulture, industry, rail, roads, sand and rock, shipping, waste, wetland. A full list of the tokens contributing to each category is provided in the supplementary material (Table S3). Throughout the process the tokens were kept associated with the date; either the year the specimen was collected, observed or the year of publication. To analyse the use of habitat words in the collected corpus, the simplified habitat terms were pooled into 20 year periods from 1780 onwards. The proportional use of each habitat term was then calculated for each period.

Statistical analysis was conducted in $\mathrm{R}$ (version 2.15.2) using generalized linear modelling with binomial errors, weighted with the number of tokens contributing to each pool. All models were checked for overdispersion using the ratio of the residual deviance and the degrees of freedom, but none were found to be overdispersed.

\section{Analysis of distribution}

Except for the rare occasions when coordinates where available with the specimen or observation, georeferencing was carried out manually according to best practise (Chapman \& Wieczorek, 2006). Error radii for coordinates were not available for most records in databases, 
but they were estimated for the coordinates georeferenced in this study, however, they were not used to select data for the analysis. The average error radius was $11 \mathrm{~km}$ and the mode and median were both $10 \mathrm{~km}$. C. vulvaria is a largely lowland species and errors in georeferencing of these magnitudes are insignificant for bioclimatic modelling at a global scale compared to the other inherent biases in these data.

Species distribution modelling was conducted using the BioVel Ecological niche modelling workflow and services (www.biovel.eu). The ecological niche modelling workflows were run on $6^{\text {th }}$ Aug 2014. The workflow uses the Maxent method based upon Phillips, Dudík \& Schapire (2004) and using the openModeller web service (de Souza Muñoz et al., 2011). Models were created using the default parameter and all 19 layers of the WorldClim global climate layers 10 arc minutes, version 1.4, release 3 (Hijmans et al., 2005).

Non-European observations used for modelling were only those locations where it was clear, either from the notes on the specimens or from Floras, that the species forms persistent population at these sites and was alien. If there was any doubt to the status, modern Floras were consulted to ascertain the persistence of the species in the area. Seventy observations were collected from locations outside Europe in southern Argentina; California; Chile; New Zealand; South Australia; South Africa; Tasmania; Tierra del Fuego (Argentina) and Victoria (Australia). The status of C. vulvaria in South Africa and New Zealand is not clear and therefore the data was not included. It is also believed to be native to Mongolia but only one observation was found. After selection, 42 observations from the naturalised range were used to model the range, however, weeding of duplicates during the workflow reduced the number to 32 . The dates of these records were from 1863 to 2012, although 86\% dated from 1950 onward. To model the realized range, all global observations were used, which resulted in 1894 observations after weeding of duplicates.

\section{Results}

\section{Text analysis}

Four habitat categories were notably more frequent than the others (Fig. 1). These categories are firstly waste, including rubbish piles, rubble, ruins and waste places of all kinds; secondly, boundaries, mainly at the base of walls; thirdly, roads and roadsides, including streets and farm 
188

189

190

191

192

193

194

195

196

197

198

199

200

201

202

203

204

205

206

207

208

209

210

211

212

213

214

215

216

217

218

tracks; and fourthly horticulture, such as gardens and other cultivated places. The habitat categories in Fig. 1 are not mutually exclusive, but often describe different aspects of the same habitat such as the proximity to landscape features, soil type, nutrient status and moisture. In summary, the habitat analysis underscores several aspects. C. vulvaria is strongly associated with humankind; natural habitats such as coastal habitat and wetlands are mentioned infrequently. C. vulvaria is intolerant of competition; none of its habitats are defined by established vegetation types, such as meadows, woodland or heaths. It is frequently associated with transport routes and it is usually associated with some form of soil disturbance.

When the use of these terms was compared over time, no significant change was found for the use of terms relating to animal waste, coastal, dry \& bare soil, habitation, hills, horticulture, industry, rail, roads, shipping and waste. Figure 2 shows the changes of eight of these categories, including the only four where there were significant changes. The significant changes were increases in the proportion of the terms related to wetland $(\mathrm{p}<0.01, \mathrm{DF}=11)$, sand and rock $(\mathrm{p}<$ $0.05, \mathrm{DF}=11)$ and disturbed and grazed land $(\mathrm{p}<0.05, \mathrm{DF}=11)$, whereas there has been a significant decrease in the proportion of terms related to boundaries $(p<0.001, D F=11)$. Of these significant changes only terms relating to boundaries were also highly frequent in the corpus (Fig. $1)$.

Those 194 habitat tokens that also had a geolocation were plotted on a map to show the spread of habitat categories (Fig. S4). Habitat categories were widely distributed rather than being clustered in single counties or in areas of a common language. There is no indication of bias in the translation and the categorization of habitats. It also implies that the results of the habitat analysis are broadly applicable.

\section{Introduction vectors, pathways and origins}

Not surprisingly, clear expressions of the introduction vector were rare on specimens and in publications. Where introduction vectors were evident they are summarised in Table 1. Ballast soil at ports was the earliest vector mentioned in the corpus and it was also most frequently mentioned. However, it stops being mentioned in the early $20^{\text {th }}$ century. Several specimens and observations implicate the transport of ore. C. vulvaria was reported on Chromite in Baltimore, USA between 1953-1958 (Reed, 1964); in Norway in 1954 (Uotila, 2001); on manganese ore in Norway between 1931-1935 and near an ore crushing plant in Kyrgyzstan in 1961 (Lazkov, Sennikov \& Naumenko, 2014). Various agricultural products are mentioned as possible vectors of 
219

220

221

222

223

224

225

226

227

228

229

230

231

232

233

234

235

236

237

238

239

240

241

242

243

244

245

246

247

248

introduction, such as grain. However, there is no mention of it being introduced with other produce commonly imported from the Mediterranean such as herbal medicines or tobacco, even though $C$. vulvaria is frequently associated with waste.

Evidence for the pathways of introductions is scant, but shipping and railways are mentioned. Although roads are the most frequently mentioned transport system (Fig. 1), it is unclear if the presence of this species on roads relates to the introduction pathway or whether roads just provide suitable habitat.

Evidence for the origin of introductions is also slim, although where the origin is mentioned it is always from a country in the Mediterranean region (Uotila, 2001). There is no evidence of return introductions from naturalised populations outside Europe.

\section{Comparing the fundamental and realized climatic niche}

The observations of $C$. vulvaria within Europe are from an inseparable mixture of stable populations and casual occurrences. It is therefore impossible to validate a model for the fundamental climatic niche of C. vulvaria. For this reason I did not attempt to refine the output of the models by adjusting their default parameters or by eliminating climate layers. It is nevertheless informative to contrast models created from the known naturalised range outside Europe with the realized range within Europe (Fig. 3, Fig. 4). The actual climatic niche, predicted from observations from the naturalised range outside Europe predicts the presence of C. vulvaria in southern and western Europe, North Africa and the Middle-east, notably, Spain, western France and Turkey (Fig. 3). The actual observations and the climate niche model created from them show a much wider distribution, which extends much further north and eastward than the niche model created from the naturalised range (Fig. 3, Fig. 4). Figure 5 shows the locations of actual observations and the dates they were made. It demonstrates that there has been a general decline in the number of observations from northern Europe, but it also suggests unevenness in surveying effort between different countries and different time periods.

\section{Discussion}

This study tracks the distribution and habitat changes of $C$. vulvaria over more than 200 years. Over this period botanical literature becomes more common and sufficiently abundant for analysis. Simultaneously, botanical specimens became more frequently collected and better documented, further adding to the analysable corpus of historical documents. 
Over the past two centuries many social, economic and technological changes have occurred that may have influenced the abundance and distribution of $C$. vulvaria. Some key events in this period are the expansion of the railway network in the $19^{\text {th }}$ century, the adoption of motorised road transport in the early $20^{\text {th }}$ century, the decline in the uses of horses for transport and agriculture in the $20^{\text {th }}$ century; the transition from sail to steam powered ships at the turn of the $20^{\text {th }}$ century; the discovery of herbicides in the mid- $20^{\text {th }}$ century and the Green Revolution in the latter half of the $20^{\text {th }}$ century. C. vulvaria to some extent benefits from its association with humankind, however, for the same reason it will be more acutely affected by cultural and technological changes than many other species.

Key habitat features of C. vulvaria were identified though text analysis. This species has been, and still is, strongly associated with humankind, both as a weed of cultivation and as a ruderal plant. The analysis identifies habitat traits such as its avoidance of competition and the association with waste. The genus Chenopodium is considered to be nitrophilous (Ellenberg et al., 1991); indeed C. vulvaria is sometimes associated with habitats linked to animal dung, however, it is much more commonly associated with other types of waste or cultivated place (Fig. 1). The temporal analysis of habitat change indicates that $C$. vulvaria is still associated with many of the same habitats as it was in the past, such as agriculture, transport and waste (Fig. 2). However, in the $20^{\text {th }}$ century habitat descriptions have included proportionally more words related to natural or semi-natural habitats, such as grazing, sand and wetland.

The reference to wetland amongst the habitats needs further explanation, because C. vulvaria is not a typical wetland plant. It does not grow in water, but colonises bare soil exposed in the summer at the margins of rivers, ditches and lakes. Thus its association with wetland is of an opportunistic colonizer of habitats free from competition, rather than a true wetland plant. The habitat where C. vulvaria has declined is along boundaries, particularly along walls, which contributed $80 \%$ of the boundary terms. C. vulvaria does not grow on walls, but beside them, which appears at first sight to be a rather non-specific habitat description. However, the margins of walls have changed considerably in the past 200 years. Walls were once built using lime mortar, rather than cement, and were frequently painted with whitewash, a mixture of calcium hydroxide and chalk. Whitewash gave the traditional white or pink colour to houses throughout Europe. Consequently, the soil in the immediate vicinity of walls would have been alkaline. $C$. vulvaria is not known as an alkaliphile, however it is clearly tolerant of high $\mathrm{pH}$ as it has been found on the ultrabasic rock chromite (Reed, 1964). Furthermore, because horses were used for 
transport and farm animals were driven along roads, the base of walls would have been strewn with animal waste. Such fertile alkaline habits do not occur by walls in modern towns and it is speculated that the technical changes in building practises and changes to transportation have contributed to the decline of C. vulvaria.

Text analysis is clearly a useful tool for environmental historians, nevertheless, it is susceptible to the fallibility and biases of authors, who may uncritically follow their forbears or write from hearsay rather than experience. Also, botanical activity is spatially and temporarily biased (Delisle et al., 2003; Schmidt-Lebuhn et al., 2013). For example, British and German botanical literature has, and continues to be, more abundant than for other countries in Europe.

Compared to the analysis of habitat, evidence for introduction vectors, pathways and origins was limited. The results, however, suggest that there were multiple vectors introducing $C$. vulvaria to northern Europe, but particularly as a grain contaminant and in ship's ballast. The frequent occurrence of $C$. vulvaria in waste perhaps indicates that its seeds were contaminants of many crops. Indeed, different descriptions accompanying specimens mentioned C. vulvaria in crops of lentils and potatoes. Unfortunately, the source of a casual introduction is rarely obvious by the time the plant is mature. Weed species that are dispersed as seed contaminants have declined throughout Europe in the $20^{\text {th }}$ century; this is, in part, a consequence of improved seed cleaning methods (Hilbig, 1987; Sutcliffe \& Kay, 2000; Lososová, 2003). Most of these weeds are considered archaeophytes to northern Europe, typical examples are Agrostemma githago L. Glebionis segetum (L.) Fourr. and Lithospermum arvense L.

Soil was used as ballast on sailing ships during the $18^{\text {th }}$ and $19^{\text {th }}$ centuries to provide stability to cargo ships when not carrying heavy loads. In ports, where heavy materials were loaded, ballast was removed and replaced by cargo. Large hills of ballast soil were a common feature of busy ports, particularly in areas of mining and heavy industry, such as in northern Europe. These ballast hills were a large reservoir of propagules for many species (Carlton, 2011). The large number of specimens and observations reflects the importance of this invasion pathway, but might be somewhat over-represented because botanists were attracted to ballast heaps as a source of novel species and because the vector of the propagules is clear in this case.

Ore is also mentioned as an introduction vector to the USA and Norway. Chromium processing began in Baltimore, USA in 1822, at which time only local chromium ore deposits were processed (Newcomb, 1994). However, by the end of the $19^{\text {th }}$ century local chromium deposits 
312 were exhausted and processing continued with imported ore until the end of the $20^{\text {th }}$ century.

313 Similarly, Norway is also a large processor of imported chromium ore, for example in 1992 the

314 country imported 187,965 tonnes of chromite ore from Turkey (Plachy, 1992). Indeed, it is likely

315 that some of the chromite imported into Baltimore was also from Turkey where chromite was

316 first mined in the $19^{\text {th }}$ century (Zengin, 1957). Therefore, it seems that exports of chromite from

317 Turkey could have been a pathway for dispersal of $C$. vulvaria during the $20^{\text {th }}$ century.

318 Animal dung is often mentioned as a growing medium for C. vulvaria, which is indirect evidence

319 for endozoochory. Certainly, other Chenopodium species are dispersed in this manner and $C$.

320 vulvaria is eaten by ruminants despite its smell (Withering 1776; Haarmeyer et al., 2010). In the

$32121^{\text {st }}$ century yet another vector of $C$. vulvaria introduction has been created, that of imported olive

322 trees (Hoste et al., 2009). These mature trees are extracted from olive groves with a large amount

323 of soil and are sold in northern Europe as horticultural novelties.

324 Though dispersal vectors are rarely mentioned in the corpus, it is clear that C. vulvaria has been

325 dispersed by a wide variety of vectors and through a number of pathways (Table 1). There are

326 historic periods associated with each vector and if this analysis was extended to more species,

327 one would be able to further refine the time frames during which these pathways were operating.

328 From the diversity of distribution vectors it is clear that C. vulvaria has been widely introduced

329 outside its natural climatic range and it often grows temporarily. However, with the exception of

330 horticultural imports, introduction pathways of $C$. vulvaria declined midway through the $20^{\text {th }}$

331 century.

332 The sporadic occurrence of $C$. vulvaria presents a problem for the selection of occurrences for 333 distribution modelling. Unless all casual occurrences are eliminated from the data before fitting,

334 the model would indicate a much broader climatic range. Separating permanent populations from

335 casual occurrences is impossible for Europe where anthropogenic disturbance and trade have

336 confused the quasi-natural distribution. However, in the naturalised range the situation is much

337 clearer. Most, if not all, modern observations of C. vulvaria in California, Australia and South

338 America appear to be from naturalised populations, that is to say, the associated meta-data

339 indicates the presence of a population and there is no indication of a recent introduction.

340 Therefore, the naturalised distribution outside Europe should reflect the fundamental climatic

341 niche of the species, as long as the distribution is at equilibrium. This assumption seems

342 reasonable since old casual records of $C$. vulvaria occur throughout the world, but naturalised

343 populations persist in only a few of those places. Clearly, introduction events were occurring all 
344 over the world for several hundred years of international trade, but $C$. vulvaria only naturalised in 345 a few of those places where habitat and climate were suitable.

346 Projecting the bioclimatic range in Europe from naturalised alien populations elsewhere predict a 347 more south-western distribution of C. vulvaria, than the modelling using all occurrences (Fig. 3,

348 Fig. 4). Yet, these rather crude models indicate that the naturalised distribution of C. vulvaria has 349 a climate much closer to that of southern Europe and North Africa than to northern and central 350 Europe. The distribution models are consistent with my hypothesis that historically C. vulvaria 351 was only present in parts of northern Europe because of repeated introductions, and that, in these 352 places, the climate is unsuitable for lasting populations to exist.

353 This conclusion assumes niche conservatism between the native and introduced populations. It 354 further assumes that the whole of the fundamental niche climate space is available to C. vulvaria 355 in its introduced range (Soberón and Peterson, 2011). Therefore, an alternative hypothesis is that 356 C. vulvaria has undergone a climatic niche shift in its introduced range such as suggested by 357 Gallagher et al. (2010). However, given that this would have had to occur in parallel on three 358 continents, this seems less plausible.

359 Discrepancies between the projected model and the realized distribution could be the result of several factors, either an incorrect model; lack of suitable habitat; spatial variation in surveying effort, or plants growing outside their actual climatic niche due to local factors. The model projecting distribution from the naturalised range is based on relatively few observations and would be improved by more data (Feeley \& Silman, 2011). Nevertheless, any distribution model of this species has to address the problem of casual occurrences. The shortage of observations from countries such as Turkey and Morocco, in apparent contrast to the models, is at least in part due to lack of collecting in these regions, but also due to the inaccessibility of the data from these countries. These results are a good reminder to those who would extrapolate native ranges onto potentially invasive ranges that it is not always possible to predict the naturalised distribution of an invasive species based upon fundamental climatic niche both because of the lack of data and indistinct native range boundaries, but also because climate is not the only determinate of 371 distribution.

\section{Conclusions}

373 Text analysis is a useful technique to study recent ecological and distributional change. Despite 374 its limitations it provided information, which would be difficult if not impossible to obtain from 375 other sources. As a larger volume of semantically enhanced biodiversity literature becomes 
376 available it will allow much more sophisticated habitat analysis covering many more species. The

377 ability to contrast data from different species will strengthen results and allow correction for

378 some of the biases. Furthermore, the development of environmental ontologies and thesauri will

379 simplify the method and improve repeatability (Buttigieg et al., 2013). This will allow over-

380 representation analysis of ontological terms associated with one species compared to the

381 incidence of these terms in the whole corpus.

382 Analysis of environmental descriptions indicates that the habitat of C. vulvaria has changed over

383 the past two centuries, particularly next to walls. Multiple vectors and pathways have been

384 involved in the human mediated dispersal of $C$. vulvaria, but different vectors and pathways were

385 active in different periods. In the past $C$. vulvaria would have been dispersed to many places

386 outside of its climatic niche. It is reasonable to believe that many of the observations of $C$.

387 vulvaria in northern Europe were the result of introductions and that a reduction in the propagule

388 pressure in recent years has consequently lead to a decline in observations of this species. It is

389 concluded that humankind spread C. vulvaria to northern Europe and created habitat for it to

390 grow and then inadvertently removed the habitat and the introduction pathways causing a decline.

391 Acknowledgements

392 I would like to thanks the following people for their help accessing collections and transcribing

393 specimen details: Ana Isabel D. Correia of the Faculdade de Ciências da Universidade de Lisboa;

394 Prof. Dr. Roberto Rodríguez Ríos from the Universidad de Concepción, Chile; Noemí Montes

395 and Neus Ibáñez Cortina of the Institut Botànic de Barcelona; Sabrina Eckert, Anton Güntsch,

396 Patricia Kelbert, Andreas Müller and Robert Vogt of the Botanischer Garten und Botanisches

397 Museum Berlin-Dahlem; Vladimir Vladimirov from the Bulgarian Academy of Sciences; Michal

398 Štefánek of Charles University in Prague; Alan Paton from the Royal Botanic Gardens, Kew;

399 Leni Duistermaat \& Dr. Hubert Turner of Naturalis Biodiversity Center and the specimen

400 digitization team at the Botanic Garden Meise and Sabine Metzger. This work has been supported

401 by the pro-iBiosphere project, which have been funded by the European Commission under the

402 7th Framework Programme (grant agreement number 312848).

403 References

404 Araujo MB, Peterson AT. 2012. Uses and misuses of bioclimatic envelope modeling. Ecology

405 93:1527-1539.

406 Atlas of Living Australia. 2014. Available at 
407

408

409

410

411

412

413

414

415

416

417

418

419

420

421

422

423

424

425

426

427

428

429

430

431

432

433

434

http://bie.ala.org.au/species/Chenopodium+vulvaria (accessed 25 February 2013).

Benito-Garzón M, Sánchez de Dios R, Sáinz Ollero H. 2008. The evolution of the Pinus sylvestris L. area in the Iberian Peninsula from the last glacial maximum to 2100 under climate change. The Holocene 18:705-714.

Berendsohn WG, Güntsch A, Hoffmann N, Kohlbecker A, Luther K, Müller A. 2011.

Biodiversity information platforms: From standards to interoperability. ZooKeys 150:71-87.

Boelcke O, Correa NM, Moore DM, Roig FA. 1985. Catálogo de las Plantas Vasculares. In:

Boelcke O, Moore DM, Roig FA, eds., Transecta Botánica de la Patagonia Austral. Proyecto

Internacional. Buenos Aires: Consejo Nacional de Investigaciones Científicas y Técnicas, 129255.

Botanical Society of Britain and Ireland. 2013. Distributions Database. Available at http://bsbidb.org.uk. (accessed 21 February 2013).

Bucher, C.T. (1806) Florae Dresdensis nomenclátor. Dresden: Walther.

Burk I. 1877. List of plants recently collected on ships' ballast in the neighborhood of Philadelphia. Proceedings of the Academy of Natural Sciences of Philadelphia 29:105-109.

Buttigieg PL, Morrison N, Smith B, Mungall CJ, Lewis SE, and the ENVO Consortium. 2013. The environment ontology: contextualising biological and biomedical entities. Journal of Biomedical Semantics 4:43.

Calflora. 2014. Information on California plants for education, research and conservation, based on data contributed by dozens of public and private institutions and individuals, including the Consortium of Calif. Herbaria. Berkeley (USA). Available at www.calflora.org (accessed 3 March 2014).

Carlton JT. 2011. Ballast. In: Simberloff D, Rejmanek M, eds. Encyclopedia of Biological Invasions. Berkeley and Los Angeles: University of California Press, 43-49.

Chapman AD, Wieczorek J. 2006. Guide to best practices for georeferencing. Copenhagen: Global Biodiversity Information Facility, 1-77.

Cheffings CM, Farrell L, Dines TD, Jones RA, Leach SJ, McKean DR, Pearman DA, Preston CD, Rumsey FJ, Taylor I. 2005. The vascular plant red data list for Great Britain. Species Status 
435

436

437

438

439

440

441

442

443

444

445

446

447

448

449

450

451

452

453

454

455

456

457

458

459

460

461

462

463

$7: 1-116$.

Ciardelli P, Kelbert P, Kohlbecker A, Hoffmann N, Güntsch A, Berendsohn WG. 2009. The EDIT

Platform for Cybertaxonomy and the Taxonomic Workflow: Selected Components. In: Fischer S, Maehle E, Reischuk R, eds. INFORMATIK 2009, Im Focus das Leben, Beiträge der 39.

Jahrestagung der Gesellschaft für Informatik e.V. (GI), 28.9. - 2.10. in Lübeck. Lecture Notes in Informatics (LNI) 154 - S. 28: 625-638.

Colling G. 2005. Red list of the vascular plants of Luxembourg. Ferrantia 42:80.

Curtis W. 1777. Flora Londinensis vol. 5. London: William Curtis.

de Souza Muñoz M, De Giovanni R, de Siqueira M, Sutton T, Brewer P, Pereira R, Canhos DAL, Canhos VP. 2011. openModeller: A generic approach to species' potential distribution modelling. GeoInformatica 15:111-135.

Ellenberg H, Weber HE, Düll R, Wirth V, Werner W, Paulissen D. 1991. Zeigerwerte von Pflanzen in Mitteleuropa. Scripta Geobotanica 18:1-248.

Feeley KJ, Silman MR. 2011. Keep collecting: accurate species distribution modelling requires more collections than previously thought. Diversity and Distributions 17:1132-1140.

Ferrez Y. 2005. Liste rouge de la flore vasculaire menacée ou rare de Franche-Comté Proposition. Les nouvelles archives de la flore jurassienne 3:217-229.

Gallagher RV, Beaumont LJ, Hughes L, Leishman MR. 2010. Evidence for climatic niche and biome shifts between native and novel ranges in plant species introduced to Australia. Journal of Ecology 98:790-799.

Groom QJ. 2013. Some poleward movement of British native vascular plants is occurring, but the fingerprint of climate change is not evident. PeerJ 1:e77.

Grulich V. 2012. Red list of vascular plants of the Czech Republic: 3rd edition. Preslia 84:631645.

Giusti L. 1997. Chenopodiaceae. In: Hunziker AT, ed. Flora fanerogámica argentina. Córdoba: Proflora-Conicet: 40: 1-53.

Haarmeyer DH, Bösing BM, Schmiedel U, Dengler J. 2010. The role of domestic herbivores in endozoochorous plant dispersal in the arid Knersvlakte, South Africa. South African Journal of Botany 76:359-364. 
464

465

466

467

468

469

470

471

472

473

474

475

476

477

478

479

480

481

482

483

484

485

486

487

488

489

490

Herbaria@home. 2013.Available at http://herbariaunited.org/atHome/ (accessed 21 February 2013).

Hilbig W. 1987. Changes in segetal vegetation under conditions of industrialized agriculture. Archives of Nature Conservation \& Landscape Research 27:229-249.

Hijmans RJ, Cameron SE, Parra JL, Jones PG, Jarvis A. 2005. Very high resolution interpolated climate surfaces for global land areas. International Journal of Climatology 25:1965-1978.

Hjelt H. 1906. Caryophyllaceae-Resedaceae. In: Conspectus Florae Fennicae in Acta Societatis pro Fauna et Flora Fennica 30. Finland: Helsingforsiae.

Hooker WJ. 1821. Flora Scotica. London: Archibald Constable and Co. \& Hurst, Robinson, and Co.

Hoste I, Verloove F. Nagels C, Andriessen L, Lambinon J. 2009. De adventievenflora van in België ingevoerde mediterrane containerplanten. Dumortiera 97:1-16.

Jalas J, Suominen J. 1980. Atlas Florae Europaeae, Vol. 5. Helsinki: The Committee for Mapping the Flora of Europe and Societas Biologica Fennica Vanamo.

Kestemont B. 2010. A red list of Belgian threatened species. Brussels: Statistics Belgium.

Delisle F, Lavoie C, Martin J, Lachance D. 2003. Reconstructing the spread of invasive plants: taking into consideration biases associated with herbarium specimens. Journal of Biogeography 30:1033-1042.

Lazkov G, Sennikov A, Naumenko A. 2014. New records in vascular plants alien to Kyrgyzstan. Biodiversity Data Journal 2:e1018.

Lejeune ALS, Courtois RJ. 1828. Compendium florae Belgicae. Leodii: P.J. Collardin.

Lososová Z. 2003. Estimating past distribution of vanishing weed vegetation in South Moravia. Preslia 75:71-79.

Macfadyen S, Kriticos DJ. 2012. Modelling the Geographical Range of a Species with Variable Life-History. PLoS ONE 7: e40313.

Meusel H, Jäger E, Weinert E. 1992. Vergleichende Chorologie der Zentraleuropäischen Flora, Vol. 1. Jena: Gustav Fischer. 
491 Mohr C. 1901. Plant Life of Alabama. In: Contributions from the United States National

492 Herbarium. Washington: US Department of Agriculture.

493 Newcomb S. 1994. A History of Chromite and Copper in Maryland: The Tyson Years. Matrix $494 \quad 3: 84-92$.

495 Phillips SJ, Dudík M, Schapire RE. 2004. A maximum entropy approach to species distribution 496 modeling. In: Proceedings of the Twenty-First International Conference on Machine Learning. 497 ACM (New York). 655-662.

498 Petitpierre B, Kueffer C, Broennimann O, Randin C, Daehler C, Guisan A. 2012. Climatic niche 499 shifts are rare among terrestrial plant invaders. Science 335:1344-1348.

500 Plachy J. 1992. The Mineral Industry of Norway in Minerals yearbook mineral industries of 501 Europe and central Eurasia. U.S. Bureau of Mines.

502 Planchuelo AM. 1975. Study of the fruits and seeds of the genus Chenopodium in -Argentina. 503 Darwiniana 19:528-565.

504 Preston CD, Pearman DA, Dines TD .2002. New atlas of the British and Irish flora. An atlas of 505 the vascular plants of Britain, Ireland, the Isle of Man and the Channel Islands. New York: 506 Oxford University Press.

507 Reed CF. 1964. A flora of the chrome and manganese ore piles at Canton, in the Port of 508 Baltimore, Maryland and at Newport News, Virginia, with descriptions of genera and species new 509 to the flora of eastern United States. Phytologia 10:324-406.

510 Sautter G, Böhm K, Agosti D. 2007. Semi-Automated XML Markup of Biosystematics Legacy 511 Literature with the GoldenGATE Editor. In: Proceedings of Pacific Symposium on Biocomputing 512 2007, Wailea (USA), January 2007. International Society for Computational Biology: 391-402.

513 Schmidt-Lebuhn AN, Knerr NJ, Kessler M. 2013. Non-geographic collecting biases in herbarium 514 specimens of Australian daisies (Asteraceae). Biodiversity and conservation 22:905-919.

515 Šerá B. 2011. Stress tolerant plant species spread in the road-net. Ecological Questions 14:45-46.

516 Smart SM, Robertson JC, Shield EJ, van de Poll HAM. 2003. Locating eutrophication effects 517 across British vegetation between 1990 and 1998. Global Change Biology 9:1763-1774.

518 Soberón J, Peterson AT. 2011. Ecological niche shifts and environmental space anisotropy: a 519 cautionary note. Revista Mexicana de Biodiversidad 82:1348-1355. 
520 Sutcliffe OL, Kay QON. 2000. Changes in the arable flora of central southern England since the 521 1960s. Biological Conservation 93:1-8.

522 Townsend Peterson A. 2011. Ecological niche conservatism: a time-structured review of

523 evidence. Journal of Biogeography 38:817-827.

524 Turner W. 1548. The names of herbes. (with an introduction, an index of English names, and an 525 identification of the plants enumerated by Turner) by James Britten. Published for the English 526 Dialect Society by N. Trübner 1881, London.

527 Uotila P. 2001. Chenopodium L. In: Jonsell B, ed. Flora Nordica. Stockholm: Bergius 528 Foundation, 4-31.

529 Van Landuyt W, Hoste I, Vanhecke L, Van den Bremt P, Vercruysse W, De Beer D. 2006. Atlas 530 van de Flora van Vlaanderen en het Brussels gewest. Nationale Plantentuin en het Instituut voor 531 Natuur- en Bosonderzoek i.s.m. Flo.Wer vzw.

532 Van Landuyt W, Vanhecke L, Hoste I, Hendrickx F, Bauwens D. 2008. Changes in the 533 distribution area of vascular plants in Flanders (northern Belgium): eutrophication as a major 534 driving force. Biodiversity and Conservation 17:3045-3060.

535 Vellend M, Brown CD, Kharouba HM, McCune JL, Myers-Smith IH. 2013. Historical ecology: 536 using unconventional data sources to test for effects of global environmental change. American 537 Journal of Botany 100:1294-1305.

538 Withering W. 1776. A botanical arrangement of all the vegetables naturally growing in Great539 Britain Vol. 1. London: Cadel and Elmsley.

540 Wróbel M, Tomaszewicz T. Chudecka J. 2006. Floristic Diversity and Spatial Distribution of 541 Roadside Halophytes along Forest and Field Roads in Szczecin Lowland (West Poland). 542 Polish Journal of Ecology 54:303-309.

543 Zengin Y. 1957. The Mode of Distribution of Chrome-Ores in Peridotites in Turkey. Bulletin of 544 the Mineral Research and Exploration Institute of Turkey 49:84-92.

545 Zhu G, Bu W, Gao Y, Liu G. 2012. Potential Geographic Distribution of Brown Marmorated 546 Stink Bug Invasion (Halyomorpha halys). PLoS ONE 7(2):e31246.

547 doi:10.1371/journal.pone.0031246 


\section{Table 1 (on next page)}

Introduction vectors gleaned from historical sources

The vectors stated or implied from specimens and publications, including the range of dates that vectors were mentioned either on specimens or in publications. 


\section{PeerJ Reviewing Manuscript}

Table 1. The introduction vectors stated or implied from specimens and publications, including the range of dates that vectors were mentioned on specimens and in publications.

\begin{tabular}{|l|l|l|l|}
\hline Vector & Dates & number & Example references and specimens \\
\hline Ballast & $1870-1912$ & 13 & $\begin{array}{l}\text { Publications: Burk, 1877; Mohr, 1901; Hjelt, } \\
1906 \\
\text { Specimens: BIRM 032912; } \\
\text { MANCH.94943.Kk803; S-H-2810 }\end{array}$ \\
\hline Grain & $1936-1964$ & 3 & $\begin{array}{l}\text { Uotila, 2001; Unaccessioned specimens from } \\
\text { Nationaal Herbarium Nederland (L); }\end{array}$ \\
\hline Wool & 1909 & 1 & $\begin{array}{l}\text { Observation by I.M. Hayward, Selkirkshire in } \\
\text { database of the Botanical Society of Britain and } \\
\text { Ireland (2013) }\end{array}$ \\
\hline Ore & $1931-1961$ & 4 & $\begin{array}{l}\text { Uotila, 2001; Reed, 1964; Lazkov, Sennikov \& } \\
\text { Naumenko, 2014; Specimen S-H-2141 }\end{array}$ \\
\hline Cork & $1956-1966$ & 1 & 1 \\
\hline
\end{tabular}


1

The use frequency of words in the collected corpus of Chenopodium vulvaria habitat descriptions

The frequency of each habitat category in the corpus of habitat descriptions from literature and specimens. The word and phrase tokens contributing to each category are presented in Table S3. 


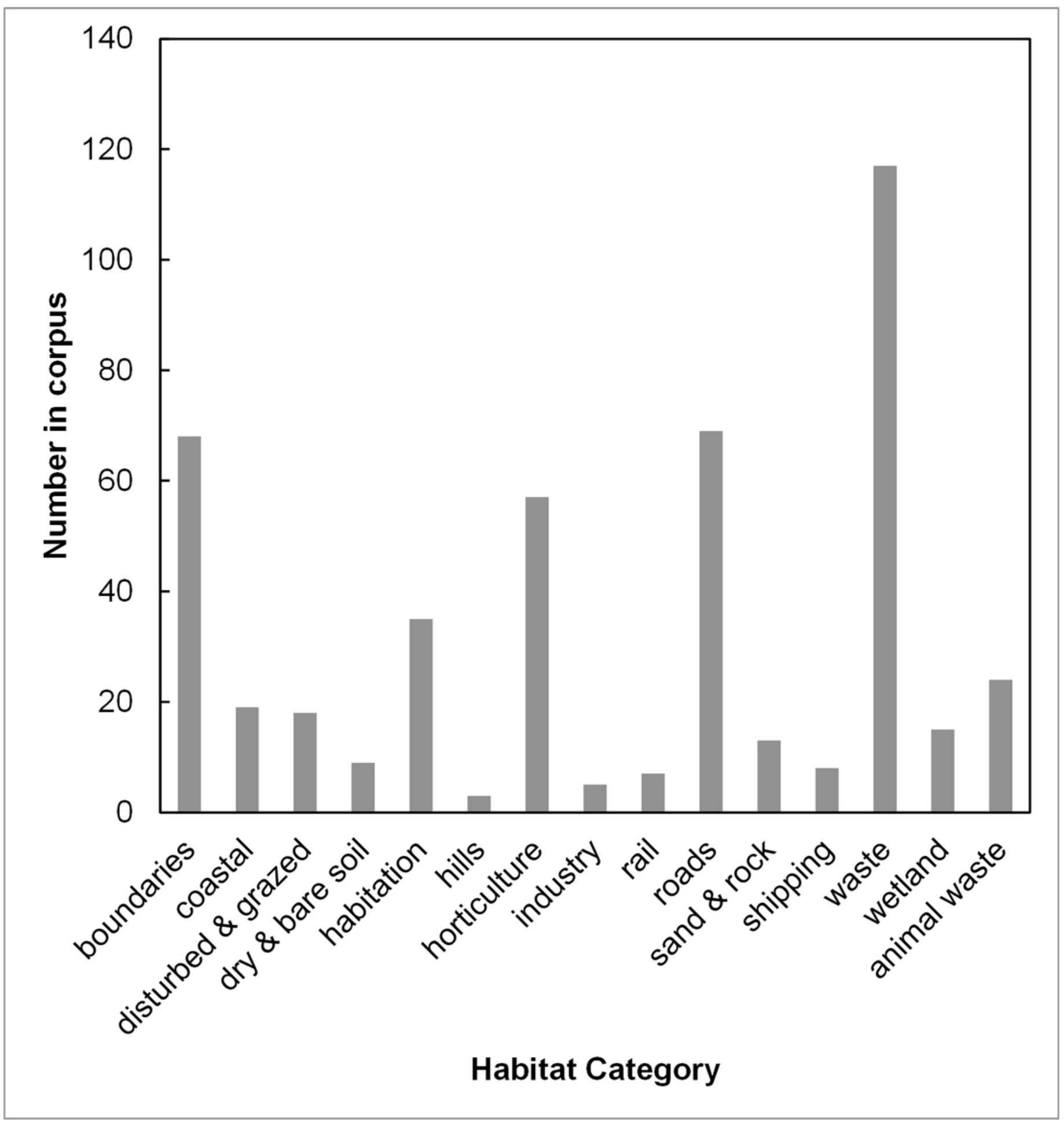




\section{2}

The change with time of habitat categories from the collected corpus of Chenopodium vulvaria habitat descriptions

A temporal analysis of the corpus of habitat descriptions from publications and specimens of Chenopodium vulvaria. The graphs show the proportion of token usage related to each habitat category for periods of 20 years. The words contributing to each habitat category are listed in Table S3. The best fit lines are from generalised linear models of the data weighted with the number of tokens contributing to each proportion. The categories wetland $(P<0.01$, $\mathrm{DF}=11)$, sand and rock $(P<0.05, D F=11)$, and disturbed and grazed $(P<0.05, D F=11)$ all significantly increased with time. Only the term boundaries decreased with time $(P<0.001$, $\mathrm{DF}=11$ ). All other categories shown in Fig. 1 did not show significant variations with time. 


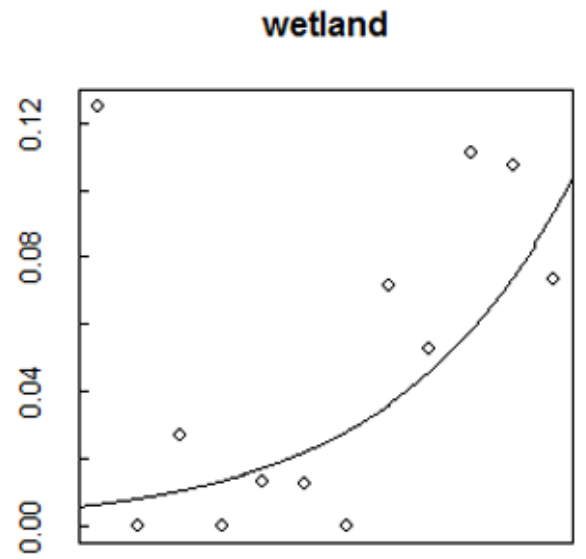

disturbed and grazed

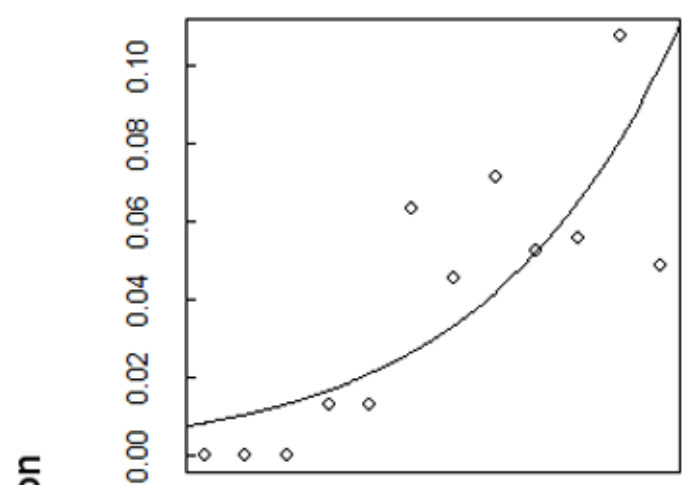

음

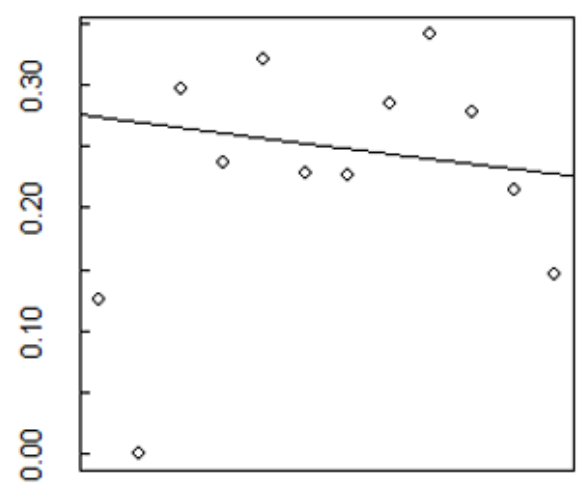

horticulture

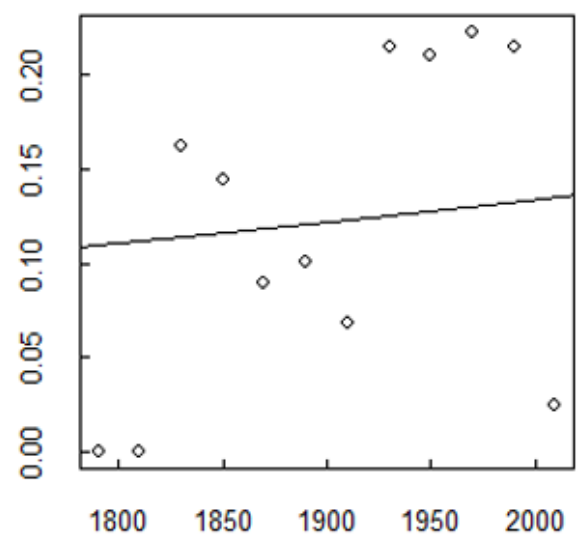

sand and rock

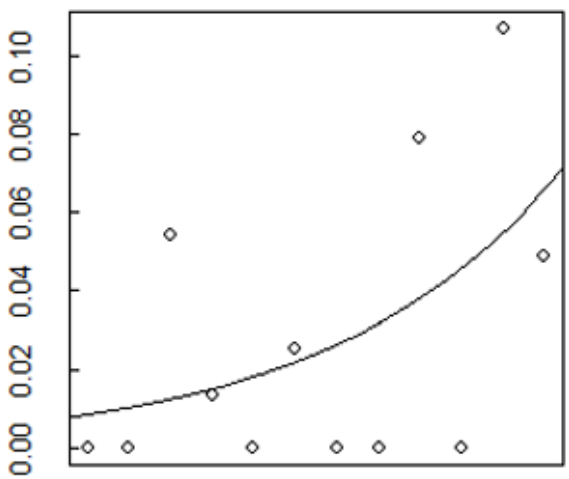

boundaries

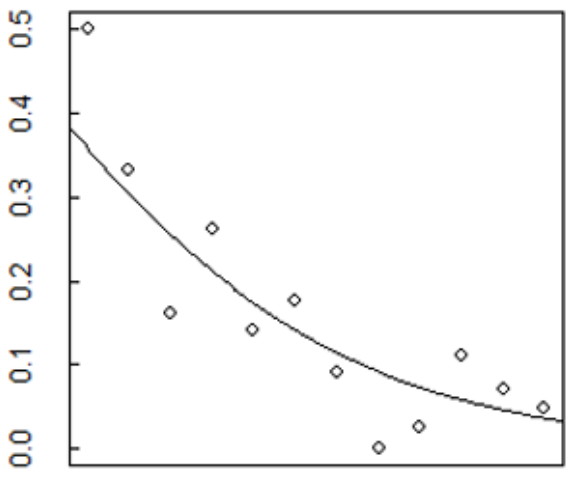

roads

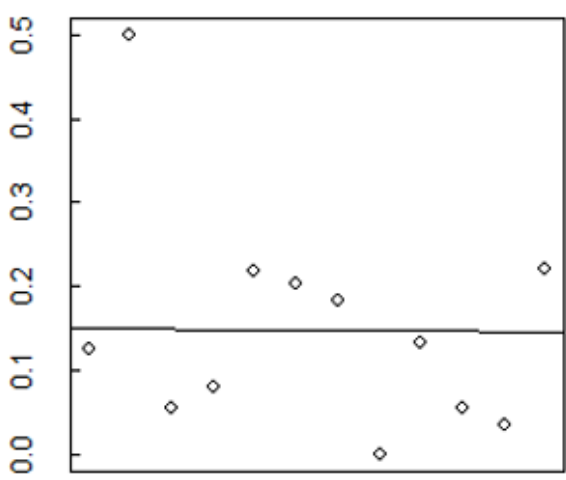

habitation

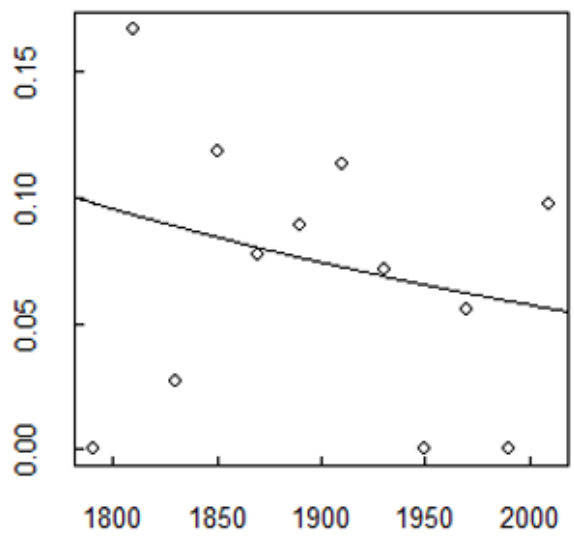




\section{3}

A distribution model created from the naturalised range of Chenopodium vulvaria outside Europe and extrapolated back to Europe.

A distribution model of Chenopodium vulvaria in Europe, North Africa and the Middle-east projected from its naturalised range in California, South America and Australia. This model aims to predict where, according to the naturalised range, the climate is suitable for persistent populations in Europe as opposed to casual occurrences. The map uses a Mollweide equal area projection.

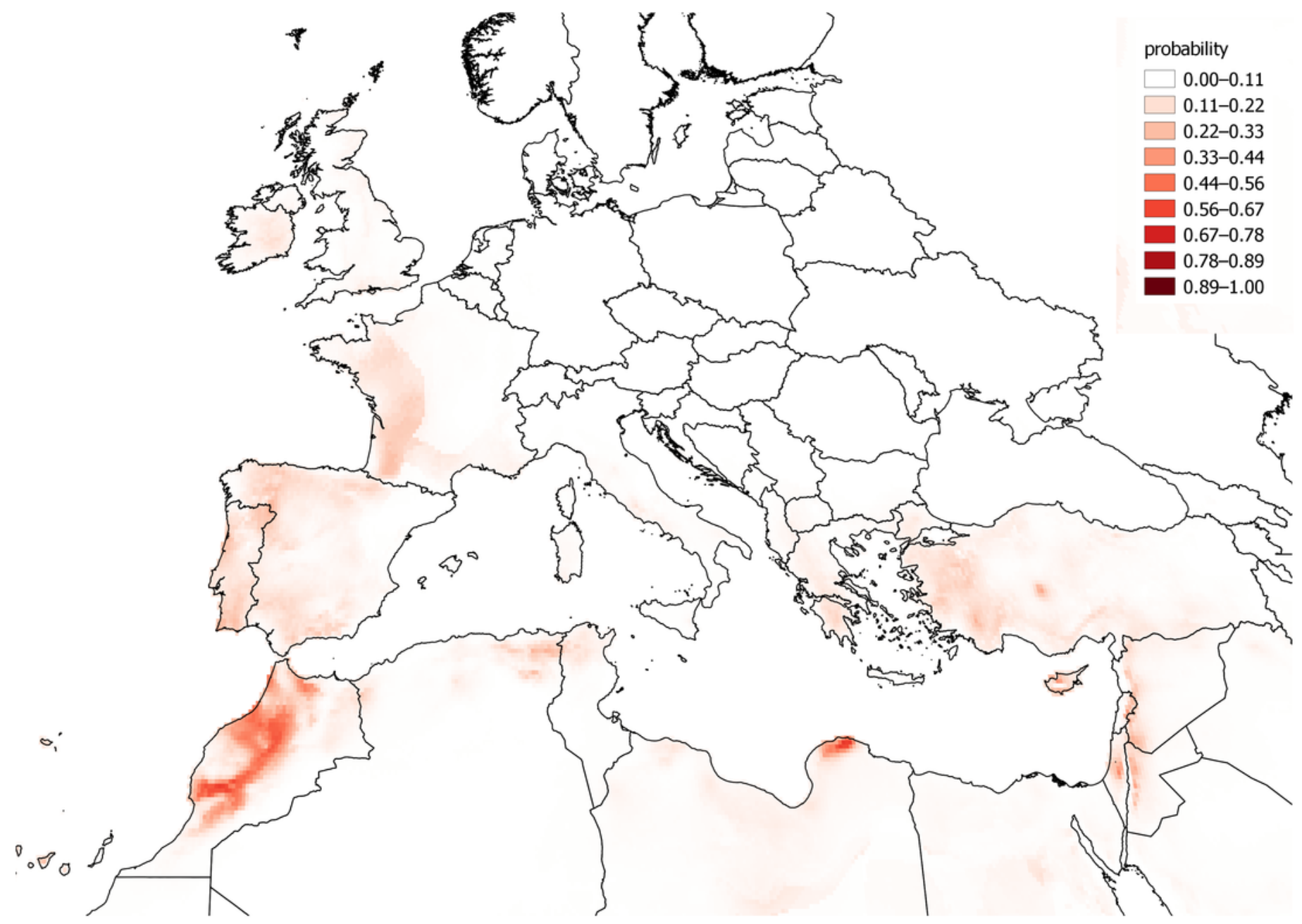




\section{4}

A distribution model of Chenopodium vulvaria created from all known locations

A distribution model of Chenopodium vulvaria in Europe, North Africa and the Middle-east created from all observations globally. This model aims to delimit the area where the climate is suitable for both stable populations and casual occurrences to occur. The map uses a Mollweide equal area projection.

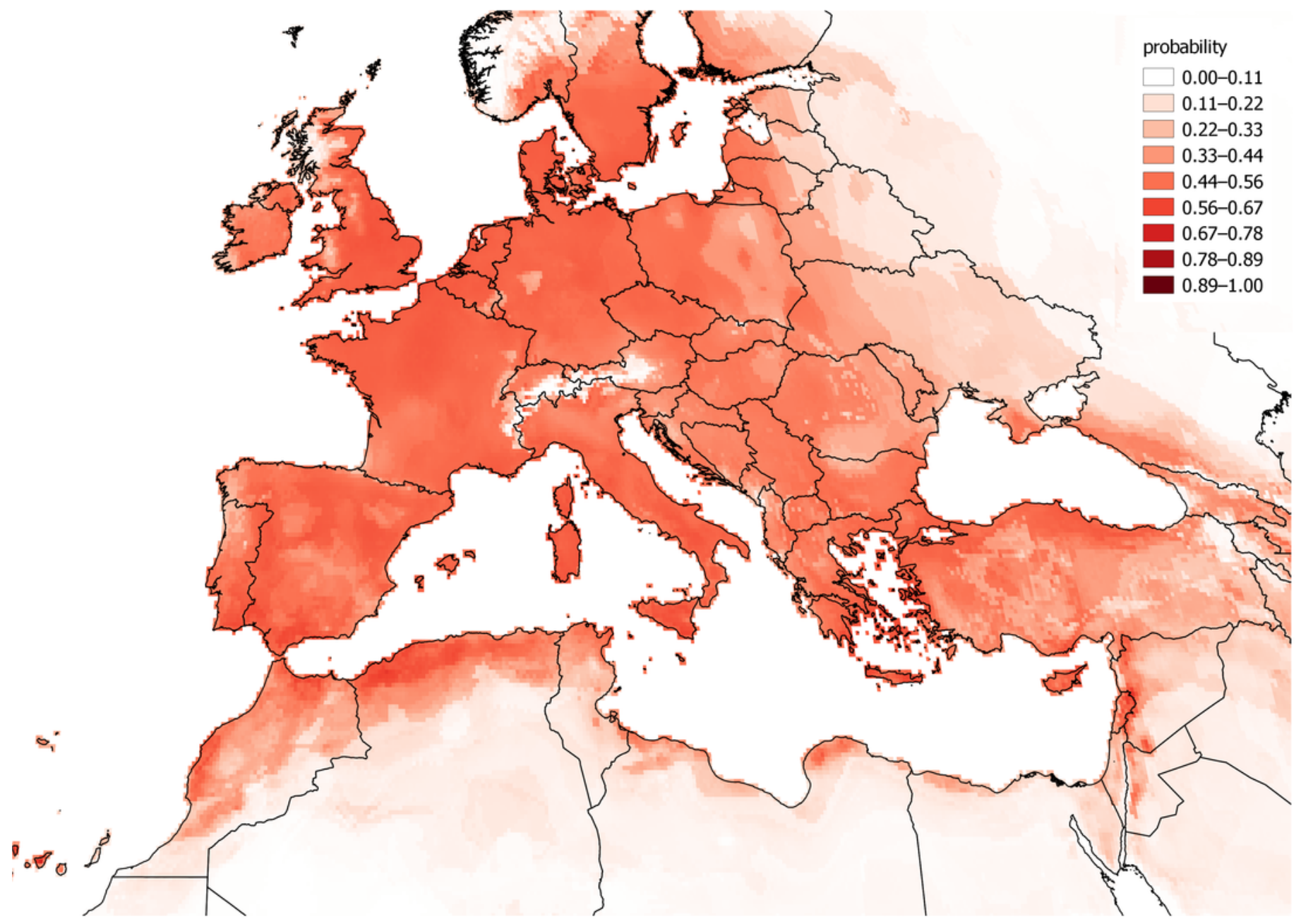




\section{5}

A dated distribution map of Chenopodium vulvaria observations from Europe, North Africa and the Middle-east

A distribution map of Chenopodium vulvaria in Europe, North Africa and the Middle-east.

Circles represent georeferenced observations either from specimens or from the literature. The colour of the points denotes the date of observation, yet to emphasise the scarcer old records the date ranges are not equal, but the data is divided into equal-sized subsets. The map uses a Mollweide equal area projection.

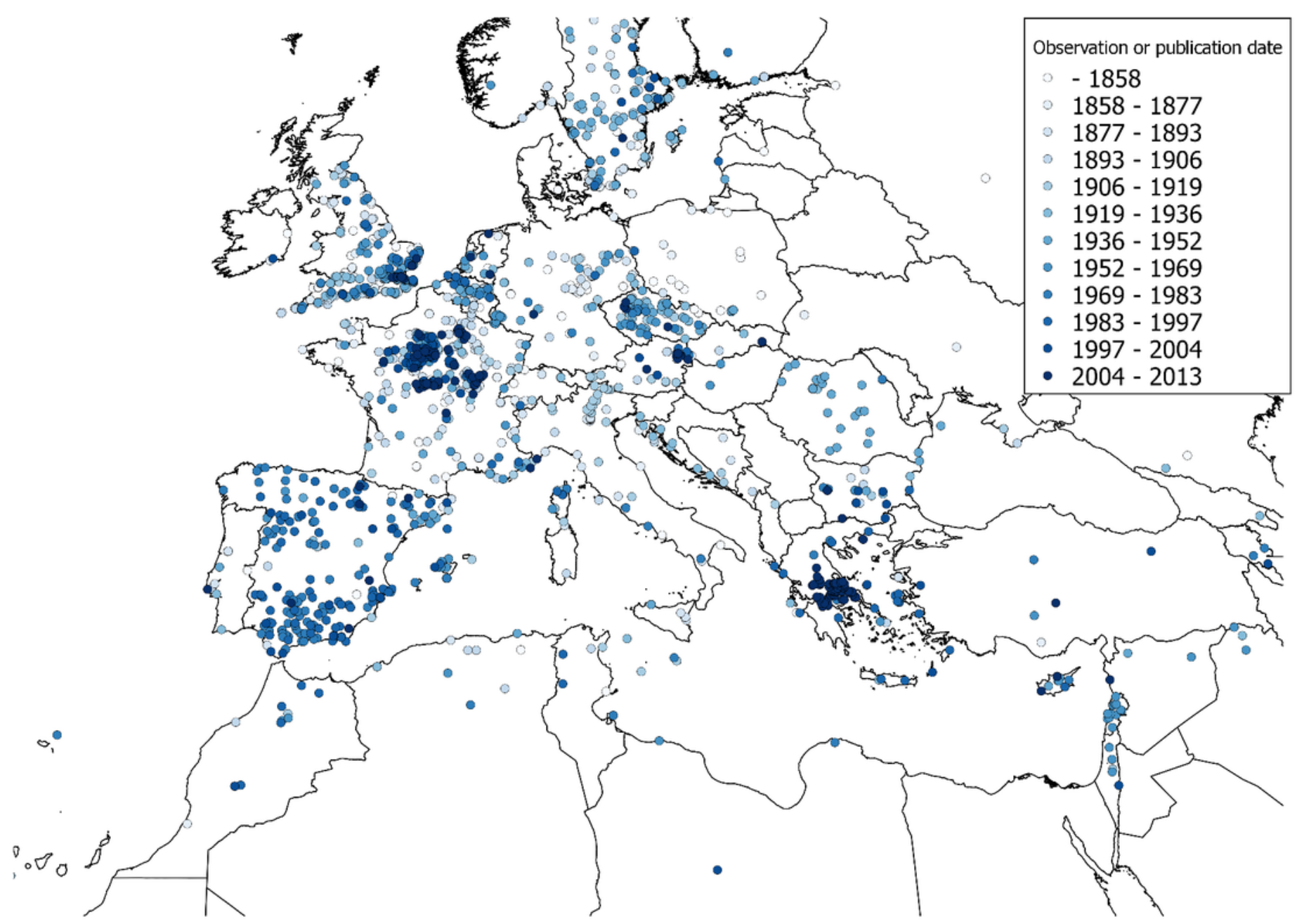

